\title{
Radionuclide Sorption Databases for Swiss Repository Safety Assessments
}

\author{
By Ian G. McKinley' ${ }^{1}$ and Helen A. Grogan ${ }^{2}$ \\ 1 Nagra, Parkstrasse 23, 5401 Baden/Switzerland \\ 2 PSI, 5232 Villigen/PSI/Switzerland (currently Intera-ECL, Henley-on-Thames, Oxon RG9 1AT/UK)
}

(Received November 6, 1989; revised January 19, 1990)

Sorption / Database / Safety assessment / Actinides / Fission products / Activation products

\section{Summary \\ The processes involved in the selection of sorption data for repository performance analysis are discussed and illustrated with reference to 11 major databases compiled for Swiss safety assessments. An approach for identification of key data require- ments is presented, from which it may be concluded that the very extensive studies to characterise a particular rock/water/ nuclide system are required in relatively few cases.}

\section{Introduction}

During the late 1970s the measurement of radionuclide sorption was a reasonably dynamic field, as reflected for example either by the range of conferences or number of papers published on the topic. About this time. however, the applicability of simple batch $K d$ s began to be questioned and the difficulties of measuring sorption data for many of the elements of interest under relevant conditions were increasingly apparent. The 1980s have thus seen a marked decrease in the number of sorption measurements reported while, at the same time, an increasing number of comprehensive nuclear waste repository safety analyses have shown the key importance of such data in ensuring adequate performance of both near- and far-field barriers.

This paper discusses the general principles of sorption database selection for safety analysis, with reference to 11 major databases compiled within the Swiss programme over the last five years or so. These databases are overviewed in order to identify key uncertainties in the context of performance assessment for both low/intermediate-level waste (L/ILW) and high-level waste (HLW) repositories. Finally, the databases for site-licensing safety analysis are considered and the requirements from field and laboratory programmes presented.

\section{Background to the Swiss programme}

Currently, it is planned that vitrified HLW (possibly including certain long-lived ILW) will be emplaced in a mined deep repository, in either the crystalline basement (at about $1200 \mathrm{~m}$ depth) or overlying sediments (at about $800 \mathrm{~m}$ ) in Northern Switzerland. L/ ILW will be emplaced at depth in a horizontally accessed repository within a hill - the host rock being marl, anhydrite or crystalline. For the HLW, a bentonite backfill presents an important transport barrier while, for the $\mathrm{L} / \mathrm{ILW}$, sorption on the large quantities of cementitious packaging/backfill is an important constraint on release. The basic characteristics of the surface soil (biosphere) are the same for both repository types and here again sorption is an important process.

In 1985 , a comprehensive safety analysis was carried out to demonstrate the basic feasibility of the disposal of all waste types in Switzerland [1]. This focussed on generic host rocks for both the HLW (crystalline) and L/ILW (marl) repositories. Since this time, the basic concept of HLW disposal in sedimentary formations has also been examined [2] while scoping safety analyses for L/ILW in specific locations in marl [3] and crystalline [4] host rocks have been completed.

\section{Available data and database selection}

Safety assessments generally utilise models which describe, in a simple manner, the performance of engineered and natural barriers during radionuclide release and transport. Several of these models require radionuclide sorption parameters to describe either the partitioning of aqueous species within a region (e.g. spreading near-field releases by temporal dilution or building up concentrations in the solid phase in the biosphere) or retardation of such species during transport. Databases for sorption of additional species - e.g. oxidants, microbial nutrients - may also be required but these are not considered here. Details of the processes included within the term 'sorption' vary between models. Basically, the partitioningtype of parameter describes radionuclide distribution between solid and liquid phases in an effectively static system. The retardation parameter may, however, tacitly include a wide range of mechanisms slowing dissolved radionuclide transport by diffusion and/or advection (e.g. filtration, ion-exclusion, matrix diffusion etc.). For safety assessment purposes, it is neither necessary, nor even desirable, for models to represent all processes occurring explicitly. Global parameters can be used as long as the model predictions can be verified against more detailed researchlevel models.

In an ideal situation, the required sorption databases would be derived from specific laboratory 
programmes complemented, where necessary, by field - or natural analogue - studies. As implied in the introduction, however, such laboratory studies are generally more difficult than would first appear.

Among the most severe problems encountered are:

1) Simulation of realistic 'in-situ' conditions

2) Characterisation of natural flow systems

3) Natural heterogeneity

4) Complexity of the near-field.

Particularly critical in (1) above is the simulation of the reducing conditions generally expected throughout much of the repository system. Apart from the practical problems of working under controlled atmosphere, many redox buffering reactions may be very slow, giving rise to fundamental problems in defining the long-term redox conditions in a particular environment [cf. 5]. Although this is of most importance for redox-sensitive nuclides, the sensitivity of some important minerals to oxidation during sampling/preparation may be a more general problem.

Point (2) refers to the use of sorption as a major (or the only) parameter characterising retardation of dissolved radionuclides, relative to pure water (or an ideal non-interacting tracer), due to interaction with surfaces. In homogeneous porous systems this may not be a serious problem although, for example, the microporous structure of highly compacted clays may limit the relevance of sorption on dispersed material to retardation in such a system. Many materials of interest are heterogeneous with localised flow paths and can be generally classified as fracture flow (or dual porosity) systems. Such systems are often rather complex on a small scale and are difficult to sample, characterise or simulate.

Natural heterogeneity (3) places inherent constraints on the detail to which any system can be characterised. Although most obvious in surface soil systems, natural systems tend to be significantly heterogeneous on all spatial scales from grain size $(\approx<\mathrm{cm})$ to formation dimensions $(\approx \mathrm{km})$.

The complexity of the engineered barrier system (4), especially for L/LLW, must also be mentioned. Such a near-field region tends to be a "chemical soup" with many complicated species (e.g. organics) and with a composition which is variable in both space and time.

Recently, there has been increased emphasis on insitu determination of sorption data by measuring the natural partitioning of various species between rock and solid phases. Such measurements may provide additional support for lab studies or confirm expected geochemistry. Resulting numerical data must be treated with extreme caution, however, as it is usually difficult to distinguish sorption from precipitation (which could imply vastly greater sorption than actually occurs) or to determine if saturation of a limited number of sorption sites has occurred. In neither of these cases is there a functional relationship between solution and solid phase concentrations.
Despite such problems, it is possible to characterise some aspects of sorption in order to provide the foundations for the construction of safety assessment databases. Inevitably, however, the final comprehensive set of databases will include input from the literature and extrapolations from measured conditions to those expected. Such extrapolations require supporting data - in particular, chemical thermodynamic predictions of the variations of aqueous phase speciation with redox conditions can be used to evaluate the consequences of poor redox simulation as considered under (1) above.

A vital aspect of database selection is definition of the purpose of the safety analysis. If the aim is simply to demonstrate the feasibility of a repository concept, it may be acceptable to choose very pessimistic sorption parameters (i.e. those leading to increased predicted releases or doses) especially for nuclides which are known to be of little significance. This must be distinguished from cases where it is intended to evaluate the relative performance of individual barriers or identify key processes influencing repository safety by sensitivity analysis. In the latter case, the database should be as realistic as possible (i.e. providing the best possible representation of behaviour under expected conditions).

Finally, it should be noted that the discussion above is focussed on databases for deterministic models as used in Swiss performance assessment. The basics are similar for probabilistic assessment databases, but the definition of the distribution of parameter values and the distinction between uncertainties due to inherent variability and those due to lack of knowledge cause additional problems.

\section{Swiss sorption databases}

In this section, the general points considered above are illustrated for the case of the databases used for Swiss performance assessments. Table 1 summarises 11 major sorption databases. It should be noted that the differences between these databases may reflect the type of model for which the data were intended. All these databases were intended for a concept demonstration type of safety analysis and hence even the "realistic" data therein tend towards conservatism. The "conservative" values are thus very pessimistic and may be considered as extreme values which maximise consequences. In addition, the values selected were particularly for "computer programs which assume the ideal distribution coefficient concept holds and hence $K d$ is defined to be a constant corresponding to the equilibrium ratio of the activity (or concentration) of a nuclide on the solid phase to that in the aqueous phase" [7]. Hence, the aim was to choose "values of $K d$ for particular rock/water/nuclide systems which would conservatively model sorption even for systems in which the $K d$ as defined is demonstrably inapplicable!" [7]. 
Table 1. Main sorption (Kd) databases used for Swiss safety analyses. Data are presented as realistic/conservative or reducing (oxidising). Units are $\mathrm{m}^{\mathbf{3}} / \mathrm{kg}$

\begin{tabular}{|c|c|c|c|c|c|c|c|c|c|c|}
\hline Bentonite & $\begin{array}{c}\text { Cement } \\
(\mathbf{1})^{\mathbf{b}}\end{array}$ & $\begin{array}{c}\text { Cement } \\
(2)^{c}\end{array}$ & Granite & $\begin{array}{l}\text { Sediment } \\
\text { (1) }^{\mathbf{a}}\end{array}$ & $\underset{(2)^{d}}{\text { Sediment }}$ & $\begin{array}{c}\text { Marl } \\
(1)^{\mathrm{e}}\end{array}$ & $\underset{(2)^{\mathrm{c}}}{\operatorname{Marl}}$ & $\begin{array}{c}\text { Surface } \\
(1)^{a}\end{array}$ & $\begin{array}{c}\text { Surface } \\
(2)^{f}\end{array}$ & $\begin{array}{l}\text { Surface } \\
(3)^{c}\end{array}$ \\
\hline \multicolumn{11}{|c|}{ 1) Actinides + daughters } \\
\hline Ac $5 / 1$ & & & $5 / .25$ & $5 / .25$ & $10 / 1$ & & & $5 / .25$ & .1 & \\
\hline Am 5/1 & 5 & .1 & $5 / .5$ & $5 / .5$ & $10 / 1$ & $5 / .5$ & $5 / .5$ & $5 / .5$ & .1 & $.1 / 10$ \\
\hline $\mathrm{Cm} \mathrm{5/1}$ & & .1 & $5 / .5$ & $5 / .5$ & $10 / 1$ & $5 / .5$ & $5 / .5$ & $5 / .5$ & .1 & $.1 / 10$ \\
\hline $\mathrm{Np} 1 / .1$ & $5(2)$ & .1 & $1 / .1$ & $1 / .1$ & $5 / .1$ & $1 / .1$ & $1 / .1$ & $1 / .001$ & .01 & $.01 / 1$ \\
\hline $\mathrm{Pa} 1 / .1$ & & .1 & $1 / .01$ & $1 / .01$ & $5 / .1$ & & $1 / .01$ & $.1 / 0$ & .1 & $.1 / 10$ \\
\hline $\mathrm{Pb} \quad 1 / .001$ & & & $1 / 0$ & $1 / 0$ & $1 / .1$ & & & $1 / 0$ & .1 & \\
\hline $\mathrm{Pu} \quad 5 / 1$ & 5 & .1 & $5 / .5$ & $5 / .5$ & $5 / .1$ & $5 / .5$ & $5 / .5$ & $1 / .1$ & 1. & $1 / 10$ \\
\hline $\mathrm{Ra} .2 / .02$ & & .1 & $1 / .05$ & $1 / .05$ & $5 / .05$ & $.1 / .01$ & $.1 / .01$ & $1 / .05$ & .1 & .1 \\
\hline $\mathrm{Rn} 0$ & & & 0 & 0 & 0 & & & 0 & & \\
\hline Th $1 / .1$ & 5 & .1 & $1 / .01$ & $1 / .01$ & $10 / 1$ & $1 / .1$ & $1 / .1$ & $1 / .01$ & 10 & 10 \\
\hline $\mathrm{U} \quad 1 / .1$ & $5(.02)$ & .1 & $1 / .05$ & $1 / .05$ & $5 / .1$ & $1 / .01$ & $1 / .01$ & $.02 / .002$ & .1 & $.1 / 1$ \\
\hline
\end{tabular}

2) Fission/activation products

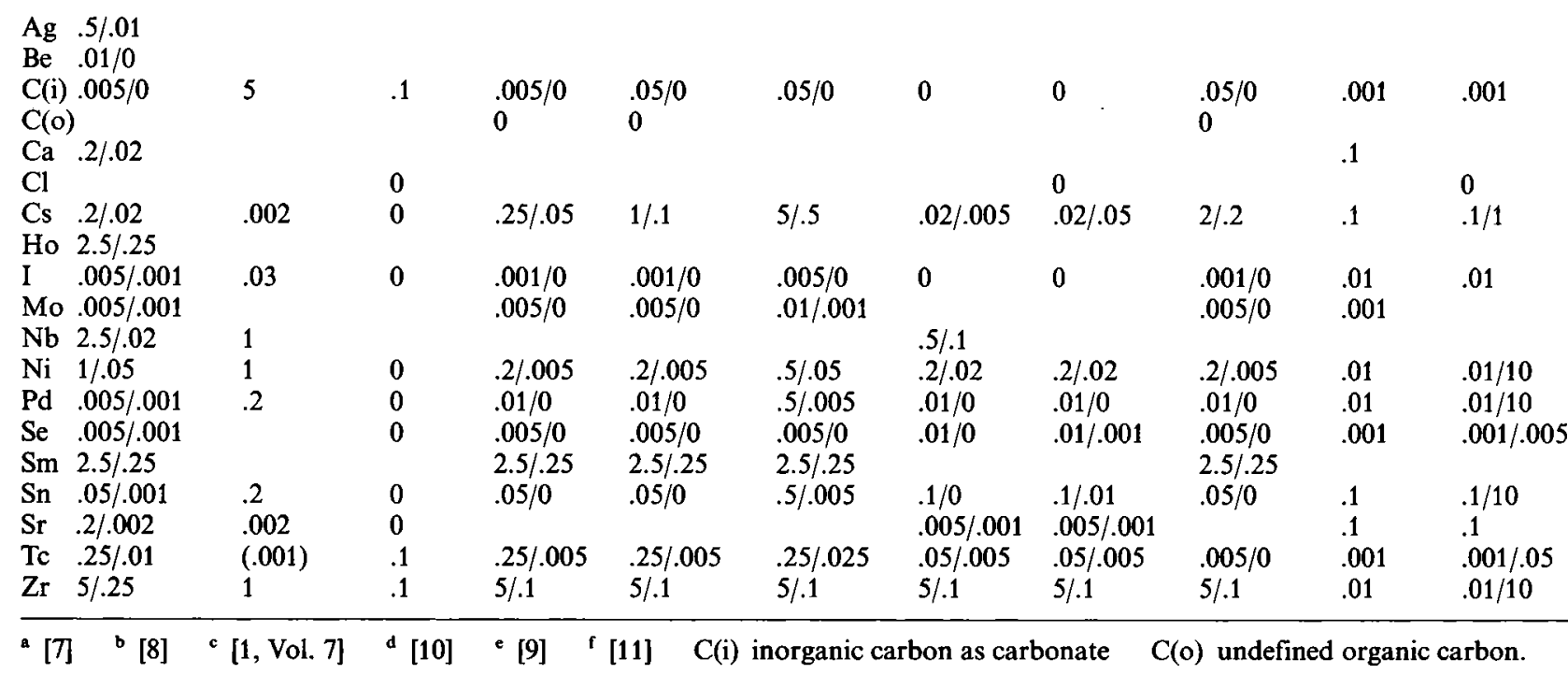

This can be illustrated by considering the Project Gewähr [1] near-field databases for bentonite and cement in Table 1. Bentonite is an important transport barrier, but in Project Gewähr it was not included in the main safety analysis chain. Transport calculations were used only to identify those radionuclides in the waste inventory which decayed to insignificance during diffusion through the backfill - e.g. shorter-lived fission products and actinide parents [cf. 6]. In the database selection, literature on sorption and diffusion measurements, speciation calculations and observations of behaviour in natural systems were combined to select both realistic and conservative $K d$ values [7]. The particular problems of applying $K d$ s to a microporous medium like bentonite were explicitly considered and data selected which would result in appropriate diffusivities [7].

For example, even though the sorption of Cs was known to be strongly concentration-dependent (increasing with decreasing Cs concentration), $K d$ values were selected for the maximum expected concentration, which should thus lead to conservative overestimation of migration. In many cases, the available sorption literature on particular elements in relevant systems was very sparse and hence particular weight had to be given to supporting data. Th, for example, could be assumed to be well sorbed due to its known geochemical immobility and, as key isotopes are sufficiently long-lived to penetrate the bentonite, the sorption value chosen does not have a significant effect on the safety analysis. Low sorption was assumed for Pd and Sn, however, due to their possible existence in solution as anionic species, and here the value assigned can significantly influence the doses predicted from these nuclides.

Two databases for cement are presented in Table 1 - Cement(1) compiled by Allard [8] and Cement(2), the database actually used in the safety assessment [1]. The Cement(1) values are based on an appraisal of the sorption literature on cement/concrete systems but did not take into account the chemical complexity of the L/ILW near-field - in particular the large quantities of organic materials which could degrade to form potential complexants. In general, therefore, the simple dataset used for safety analysis represents rounded down numbers to try to take this 
uncertainty into account. It should be noted that organic complexants are present in low concentrations relative to ligands like $(\mathrm{OH})^{-}$, while radionuclides are at trace concentrations relative to elements like $\mathrm{Ca}$ which may complex to the organics. Thus, the consequences of such organics on the sorption of most nuclides may be very small. Nevertheless, significant sorption is assumed only for the actinides, carbonate, $\mathrm{Tc}$ (assuming reducing conditions) and $\mathrm{Zr}$.

Five deep-geological databases are shown in Table 1, one for granite, two for deep sedimentary rocks and two for marl. Even though these rocks are quite different, the databases are seen to be very similar. In all cases water flow is assumed to occur predominantly in fractures. Advecting water thus contacts only the fracture infilling minerals which tend to be rather similar (clay minerals, calcite, iron oxides/ hydroxides, etc.) as is the expected water chemistry in the fissures $(\mathrm{pH} 7-8.5$, reducing, ionic strength $\approx 0.2 \mathrm{M}$ ).

Generally, it can be noted that in all cases the actinides are assumed to be strongly sorbed (realistic $K d \geq 1 \mathrm{~m}^{3} / \mathrm{kg}$ ) as are $\mathrm{Sm}, \mathrm{Pb}$ and $\mathrm{Zr}$. In the intermediately sorbed range $\left(0.05 \leq K d<1 \mathrm{~m}^{3} / \mathrm{kg}\right)$ lie $\mathrm{Ra}, \mathrm{Cs}$, $\mathrm{Nb}, \mathrm{Ni}$ and Tc. Those nuclides with realistic $K d$ values $<0.05 \mathrm{~m}^{3} / \mathrm{kg}$ are generally species which are expected to be present in an anionic form, although zero sorption is also assumed for $\mathrm{Rn}$ and organic carbon.

The volume of data is too great to be considered in detail, but some of the principles of database selection can be illustrated by considering the actinides plus their daughters.

$\mathrm{Am}$ and $\mathrm{Cm}$ are generally observed to be very strongly sorbed - so much so that, in the HLW base case, all isotopes would decay to insignificance during transport through the bentonite backfill. The geochemical evidence matches that from chemical thermodynamic modelling [e.g. 12] which predicts predominance of the free trivalent cation or cationic complexes over the relevant range of water chemistries considered. This consistent picture allows high sorption values to be selected, which are also taken to apply to Ac due to geochemical similarity. The data selected in this latter case are relatively unimportant due to the short half-life of all Ac isotopes.

The situation with regard to $\mathrm{Pu}$ is less clear as, despite its commonly observed high sorption, it has an extremely complex chemistry. Nevertheless, although different thermodynamic data sets gave quite different predicted speciation, a predominance of cationic complexes is observed under the expected $\mathrm{pH} /$ redox conditions [12]. Again, due to extensive sorption on bentonite, releases from the near-field tend to be very low. Although high far-field sorption values are selected, they do not critically affect the safety case.

$\mathrm{Np}, \mathrm{U}$ and $\mathrm{Th}$ are the key long-lived actinide parents which will tend eventually to break through the geosphere barrier and for which sorption plays a critical rôle in determining eventual release. Under reducing conditions, $\mathrm{Np}$ is again generally observed to be well sorbed, although the thermodynamic modelling generally predicts predominance of an uncharged hydroxo complex. Realistic sorption data for $\mathrm{Np}$, Th and $U$ tend to be similar as all are expected in the IV oxidation state in the specified reference waters. The lower values for conservative $K d$ s for Th and $U$ result from the model predictions of possible anionic complexes of these species in these reference waters.

The realistic values for the daughters $\mathrm{Pa}, \mathrm{Pb}$ and $\mathrm{Ra}$ are estimates based on geochemical analogues or known geochemical behaviour. As relevant nuclides are, in any case, transported through the geosphere in equilibrium with long-lived parents, the conservative values for granite and sediment (1) may be unduly pessimistic. The values for sediment (2) are better representatives of currently available data [10].

The final datasets in Table 1 refer to surface deposits. Here a very important distinction must be made between surface (1) - selected for transport calculations in surficial, oxidising aquifers and surface (2)/ surface (3) which are effectively soil-partitioning coefficients used for a biosphere transport code. In the geosphere transport models a low $K d$ is conservative as it leads to overprediction of migration but, in the biosphere model used, a high $K d$ is conservative as it overpredicts the extent of radionuclide accumulation in soil giving rise to external radiation exposure, root uptake by crops, exposure by soil resuspension/inhalation, etc. Given this fundamental difference between the databases, the individual data therein are seen to be generally comparable. Some strange discrepancies do, however, exist. For example, among the fission products, the conservative values for $\mathrm{Ni}, \mathrm{Pd}$ and $\mathrm{Sn}$ vary considerably. Some of these differences may be attributed to the increased possibility of microbially mediated immobilisation in the soil zone, but much of the uncertainty is due to limited sorption literature, lack of knowledge about the environmental chemistry of these elements and major gaps in available thermodynamic databases. Although the soil data tend to be much more empirical, the literature - particularly in terms of field observations - is much more extensive [e.g. 13]. Radioecological studies of bomb-fallout and nuclear accidents, routine operational releases from nuclear installations, areas of high natural series concentrations etc. have provided a vast database from which a fairly consistent picture of the behaviour of a wide range of nuclides in soils and surface aquifers emerges.

\section{Application of sorption data in safety assessments}

In the previous section an indication of the process of database selection was given. In many cases, it is clear that the criteria for selection are less rigorously applied for elements which are considered to be of little relevance than is the case for key elements. The choice of key elements is by no means arbitrary. The starting points are inventories of all of the nuclides contained 
within particular waste types [e.g. 14]. Many of these are short-lived and will decay to insignificance $(\approx<1$ $\mathrm{Bq} / \mathrm{g}$ waste, say) during storage or during the minimum life of the canister and thus can be ignored in the long-term safety analysis. The remaining nuclides form the basis for the lists given in Table 1 .

When the full safety analysis chain is considered, however, it becomes clear that only a few of these nuclides are important in the base case (i.e. normal evolution scenario). The near-field models indicate trivially low release rates of many nuclides due to the low degradation rate of the waste matrix or low solubility in the near-field environment. Including sorption in the backfill may allow further nuclides to be discounted even if, as in most cases, far-field sorption would be even more efficient. To evaluate the performance of the multi-barrier concept, it is important to evaluate near-field sorption realistically. For example, a simple 1D diffusion calculation for the reference Swiss HLW repository indicates that the only fission/activation products released at significant concentrations would be Se-79, Tc-99, Cs-135, Sn-126 and Pd-107. Such calculations also indicate that all transuranics except Np-237 would be released in negligible quantities. Further 2D calculations indicate that, if the far-field hydrology can be well defined, the releases of even $\mathrm{Np}$ could be negligibly small [15].

For the particular case of bentonite, it can be concluded that sufficiently high sorption of all cations/ cationic complexes or neutral complexes has been well enough established. In a realistic assessment, therefore, only extremely long-lived nuclides (e.g. $U$ isotopes) and their daughters will be released in significant quantities. For many such nuclides (U-235, U238, Th-232), the safety assessment could be considered superfluous as they are probably present at saturation levels in natural waters and the waste component cannot be distinguished from natural levels. The key nuclides are long-lived and expected to be present as anions (e.g. Se-79 as selenide) or possibly as anionic complexes (e.g. Sn-126 or Pd-107). Experimental measurements showing even limited sorption (e.g. $K d \approx 0.01 \mathrm{~m}^{3} / \mathrm{kg}$ ) of these elements could, however, lead to insignificant predicted doses (which, in the latter case, may be supported by data indicating that the assumed anionic complexes are inappropriate).

The cementitious near-field for L/ILW is currently assumed to function more as a geochemical buffer and less as a transport barrier. Nevertheless, sorption of particular elements in concrete is observed to be very high (e.g. actinides - cf. [8]). This, given their relatively low concentration, may be sufficient to decrease releases to negligible levels due to the process of temporal dilution (spreading releases over a longer period of time). Sorption of carbonate is also taken to be sufficiently high to remove all concern about inorganic $\mathrm{C}-14$ releases in this form even though, in this case, sorption is a poor description for the carbonate mineral formation which is probably involved. In general, however, the geochemical rôle for concrete/cement is easier to justify than retardation, because of uncertainty about the microscopic description of flow paths through this material (e.g. due to long-term fracturing processes).

In the base case, therefore, only a relatively few elements need to be considered for far-field transport. U-235, U-238 and Np-237 generally emerge at significant levels due to their long half-lives, but Th-232 can usually be ignored due to relatively lower activity inventories and low solubility/known geochemical immobility. Given the previous arguments of the ubiquitous presence of the $U$ isotopes, it is reasonable to consider only $\mathrm{Np}-237$ (and its daughters) as an anthropogenic perturbation of the natural system and hence its sorption in the geosphere is a key parameter.

A number of long-lived fission/activation products may also survive far-field transport (e.g. Se-79, Tc-95, Cs-135, Sn-126 and Pd-107 from HLW and, additionally, I-129, Cl-36 and Ni-59 from L/ILW). Even limited sorption $\left(K d \approx 0.01 \mathrm{~m}^{3} / \mathrm{kg}\right)$ would, nevertheless, reduce releases of most of these elements to negligible levels - which may be possible to justify for all but $\mathrm{Se}, \mathrm{I}$, and $\mathrm{Cl}$. Of these, chloride is least likely to be sorbed and only non-sorptive retardation (e.g. matrix diffusion) or dilution could reasonably be expected to be significant in the geosphere. Some sorption of iodide/selenide (or iodate/selenate) may be possible, but would be very dependent on the presence of some particularly selective minerals (e.g. sulphides) or microbial activity.

In the biosphere, the key elements are thus $\mathrm{Np}$ and its daughters (which now have to be considered separately) and the anionic fission products (with some additional longer-lived fission products as second priority). A recent analysis of $\mathrm{Np}$ and I [16] presents best estimate $K d$ values and gives maximum/ minimum values from explicit consideration of the properties of a range of soil types.

\section{Safety analysis developments and key data requirements}

From the previous discussion, it is clear that only a few nuclides are of key importance (less than 10 for the near-field and far-field, with a few more for the biosphere, where decay chain daughters need to be considered separately). Because of this, recent Swiss scoping safety analyses have used much reduced databases (cf. Table 2). For particular waste types, a few key elements are selected and these are used to evaluate the sensitivity of calculated doses to various base-case parameter variations. This approach is applicable for concept evaluation and, for example, readily illustrates the influence of various far-field flow scenarios on resultant releases to the biosphere and doses to man [2].

The next generation of safety assessments will be site-specific and involve detailed sensitivity analysis to provide feedback for layout planning, design optimisation, waste acceptance criteria and oper- 
Table 2. Sorption data (or ranges) used for recent Swiss scoping safety analyses. Data are presented as $\mathrm{Kd}$ values $\left(\mathrm{m}^{3} / \mathrm{kg}\right)$

\begin{tabular}{llllll}
\hline & Cement $^{\mathrm{a}}$ & Marl $^{\mathrm{a}}$ & Granite $^{\mathrm{b}}$ & Clay $^{\mathrm{c}}$ & Sand $^{\mathrm{c}}$ \\
\hline $\mathrm{C}(\mathrm{i})$ & 0.01 & 0.005 & 0.005 & & \\
$\mathrm{C}(\mathrm{o})$ & 0 & 0 & 0 & & \\
$\mathrm{Cl}$ & 0.001 & 0.001 & 0 & & \\
$\mathrm{Cs}$ & 0.001 & $0.1 / 0.02$ & 0.25 & & \\
$\mathrm{I}$ & & & & $0.005 / 0$ & 0 \\
$\mathrm{~Np}$ & 1. & 1. & 1. & $10 / 0.01$ & $2 / 0.002$ \\
$\mathrm{Se}$ & & & & $0.005 / 0$ & 0 \\
\hline
\end{tabular}

${ }^{a}$ [3] b [4] c [2]

$\mathrm{C}(\mathrm{i})$ inorganic (carbonate) carbon $\mathrm{C}(\mathrm{o})$ undefined organic carbon.

ational specification. From the modelling side, an important development will be the linking of simple models of release, near-field and far-field transport and biosphere uptake to provide a tool for examining the repository system as a whole. Preliminary calculations with comprehensive conservative sorption datasets will be used to identify key nuclides (for both base-case and altered evolution scenarios).

The sorption data for the key elements, however, must be as realistic as possible - measured on an appropriate range of materials in a rigorously specified chemical environment (including trace components such as organics). In most cases, it is unlikely that a simple $K d$ parameter will be acceptable here and the observed concentration dependence, kinetics, reversibility etc. would need to be taken into account. For the safety assessment modelling, a mechanistic model would not be required, but a mechanistic interpretation of sorption behaviour or model validation by field studies or natural analogues would be necessary to justify the extrapolations in space and time involved.

The key elements identified depend, to some extent, on the waste and disposal concept involved. In the Swiss programme, Np-237 and Se-79 are likely to remain important examples of a very long-lived actinide and a mobile, long-lived fission product and extensive characterisation of these elements is planned. The provision of better thermodynamic data, however, may allow elements like Sn and Pd to be discounted on the basis of either very low solubility or the nonexistence of proposed anionic complexes. Consideration of sorption in a safety assessment context thus allows not only key elements to be identified but also research effort to be focussed on the areas in which the final aim of the work - demonstration of repository safety - can most efficiently be realised.

\section{Acknowledgements}

The sorption databases described in this report were compiled by, or with input from, many of our col- leagues at Nagra, PSI and Nagra contractors to whom we extend our thanks. The authors, however, accept full responsibility for the interpretation, comparison and synthesis which form the basis for this paper.

Thanks in particular to Drs. B. Baeyens, J. Boehringer, M. Bradbury and F. van Dorp for their comments on an early manuscript and to Drs. J. Hadermann, C. McCombie and P. Zuidema for their support of this paper.

\section{References}

1. Nagra: Project Gewähr Feasibility Study; Nagra Gewähr Report series, NGB 85-01 to NGB 85-08 (in German), NGB 85-09 (English summary), Nagra, Baden, Switzerland 1985.

2. Nagra: Sedimentstudie - Zwischenbericht 1988 Möglichkeiten zur Endlagerung langlebiger radioaktiver Abfälle in den Sedimenten der Schweiz; Nagra Technical Report series, NTB 88-25, Nagra, Baden, Switzerland 1988.

3. Nagra: Untersuchungen zur Standorteignung im Hinblick auf die Endlagerung schwach- und mittelaktiver Abfälle Berichterstattung über die Untersuchungen der Phase $1 \mathrm{am}$ potentiellen Standort Oberbauenstock (Gemeinde Bauen, UR); Nagra Technical Report series, NTB 88-18, Nagra, Baden, Switzerland 1988.

4. Nagra: Untersuchungen zur Standorteignung im Hinblick auf die Endlagerung schwach- und mittelaktiver Abfälle Berichterstattung über die Untersuchungen der Phase $1 \mathrm{am}$ potentiellen Standort Piz Pian Grand (Gemeinden Mesocco and Rossa, GR); Nagra Technical Report series, NTB 8819, Nagra, Baden, Switzerland 1988.

5. Lindberg, R. D., Runnells, D. D.: Groundwater redox reactions: An analysis of equilibrium state applied to Eh measurements and geochemical modelling; Science 225, 925927 (1984).

6. McKinley, I. G.: The geochemistry of the near-field; Nagra Technical Report series, NTB 84-48, Nagra, Baden, Switzerland 1985.

7. McKinley, I. G., Hadermann, J.: Radionuclide sorption database for Swiss safety assessment; Nagra Technical Report series, NTB 84-40, Nagra, Baden, Switzerland 1984.

8. Allard, B.: Radionuclide sorption on concrete; Nagra Technical Report series, NTB 85-21, Nagra, Baden, Switzerland 1985.

9. Allard, B.: Radionuclide sorption on carbonate-clayish rock; Nagra Technical Report series, NTB 85-20, Nagra, Baden, Switzerland 1985.

10. Wittwer, C., McKinley, I. G. (eds.): Geochemical database for the sediment report; Nagra Technical Report series, NTB 89-05, Nagra, Baden, Switzerland 1989.

11. Jiskra, J.: Database for radionuclide transport in the biosphere - Nuclide-specific and geographic data for Northern Switzerland; Nagra Technical Report series, NTB 85-15, Nagra, Baden, Switzerland 1985.

12. Schweingruber, M.: Actinide solubility in deep groundwaters - Estimates for upper limits based on chemical equilibrium calculations; Nagra Technical Report series, NTB 83-24, Nagra, Baden, Switzerland 1983.

13. Coughtrey, P. J., Jackson, D., Thorne, M. C.: Radionuclide distribution and transport in terrestrial and aquatic ecosystems, Vol. 6, A. A. Balkema, Rotterdam 1985, p. 194.

14. Nagra: Inventar und Charakterisierung der radioaktiven Abfälle in der Schweiz; Nagra Technical Report series, NTB 84-47, Nagra, Baden, Switzerland 1984.

15. Hopkirk, R. J., Gilby, D. J., Wagner, W. H.: Modelling of solute transport in the near-field of a high-level waste repository; Nagra Technical Report series, NTB 85-26, Nagra, Baden, Switzerland 1985.

16. Baeyens, B., Grogan, H. A., van Dorp, F.: The transport of contaminated groundwater to soil; Nagra Technical Report series, NTB 89-20, Nagra, Baden, Switzerland 1990. 